\title{
MgO/CaO-loaded porous carbons for carbon dioxide capture
}

\author{
Effects accompanying regeneration process
}

\author{
Jacek Przepiórski • Adam Czyżewski • \\ Robert Pietrzak $\cdot$ Beata Tryba
}

Received: 4 January 2012/ Accepted: 23 February 2012/Published online: 18 March 2012

(C) The Author(s) 2012. This article is published with open access at Springerlink.com

\begin{abstract}
Nanoporous carbons loaded with both $\mathrm{MgO}$ and $\mathrm{CaO}$ were prepared by a simple heating of mixtures consisting of poly(ethylene terephthalate) and natural dolomite. Preparations were carried out at temperatures ranging from 850 to $1,000{ }^{\circ} \mathrm{C}$ that ensured complete thermal decomposition of the dolomite contained in the mixtures to the oxides. An influence of the PET/dolomite weight ratio and temperature of the preparation process on the porosity of the obtained composite products and on $\mathrm{CaO}$ and $\mathrm{MgO}$ crystallite sizes are discussed using the results of nitrogen adsorption/desorption at $77 \mathrm{~K}$ and X-ray diffraction analyses, respectively. Performances of the hybrid materials as sorbents for carbon dioxide were examined using thermogravimetric analyses. Finally, possibility of regeneration of the spent sorbent materials together with a side-effect accompanying this process are discussed on the basis of thermogravimetric measurements. As found, a part of $\mathrm{CO}_{2}$ captured by the hybrid sorbents gets adsorbed weakly and another portion is fixed strongly. During thermal regeneration, the strongly fixed $\mathrm{CO}_{2}$ reacts with carbon material. In this way small fraction of a sorbent is lost.
\end{abstract}

Keywords Porous carbon $\cdot \mathrm{MgO} \cdot \mathrm{CaO} \cdot \mathrm{CO}_{2}$. Sorption $\cdot$ Regeneration

\footnotetext{
J. Przepiórski $(\bowtie) \cdot$ A. Czyżewski · B. Tryba

West Pomeranian University of Technology, ul. Pułaskiego 10,

70-322 Szczecin, Poland

e-mail: jacek.przepiorski@zut.edu.pl

R. Pietrzak

Faculty of Chemistry, Adam Mickiewicz University,

Grunwaldzka 6, 60-780 Poznan, Poland
}

\section{Introduction}

Porous carbon materials are widely used as adsorbents for purification of gases and liquids. Because of a wide spectrum of applications, various sorts of these specific materials are offered on the market [1]. Depending on the preparation route, raw materials, and eventually on the additional treatments, properties of activated carbons may be very different. Activated carbons may reveal differences in pore structure and specific surface area, which are one of key factors influencing adsorption. For example, microporous carbons usually effectively adsorb contaminants of a small molecular size and mesoporous ones are efficient for adsorption of large molecules [2, 3]. Besides porosity, presence of different oxygen-containing surface functional groups gives to the activated carbons specific features, like enhanced selectivity toward certain adsorbates. For instance, high content of the oxygen functionalities on the surface of activated carbons is beneficial for adsorption of $\mathrm{SO}_{2}, \mathrm{CO}_{2}$, or phenols [4-6].

Both efficiency and selectivity of carbon adsorbents can be modified by loading to their structure suitable additives, intentionally chosen for a specific application [7]. Therefore, porous carbon materials supporting certain chemicals are used as highly effective adsorbents for special applications, including respiratory protection or purification of air for clean rooms [8,9]. The additive-loaded activated carbons are also used as catalysts support [10] or as materials being highly efficient during removal of contaminants from air in closed ventilation systems. The high parameters of such composite sorbents are a consequence of a synergic effect, resulting from both physical adsorption and chemical interaction between the additive present in the material and the target adsorbate. Loading of additives into porous carbons is typically realized through impregnation of commercially available carbon adsorbents with suitable organic or 
inorganic agents [11]. However, heating of some carbon precursors mixed with certain chemicals can be also used as an appropriate method to prepare porous carbon materials carrying additives [12, 13].

In this work, we present our results on the preparation and properties of carbon adsorbents loaded with two basic oxides, $\mathrm{CaO}$ and $\mathrm{MgO}$. These hybrid sorbents were obtained through pyrolysis of natural dolomite contained in mixtures with poly(ethylene terephthalate) (PET). The natural dolomite was a source of the oxides and the latter served as a synthetic carbon precursor. Till now such a one-step route was not reported. Selection of the precursors for preparations was not unintended. We believed that because of $\mathrm{MgO}$ and $\mathrm{CaO}$ content, obtained porous products would be active in removal of gaseous contaminants of acidic character from air. Porous carbon materials alone $[14,15]$ as well as $\mathrm{MgO}$ and $\mathrm{CaO}[16,17]$, are known as revealing a potential in fixation of such gases. For that reason, these find an application for removal of acidic gases, principally $\mathrm{SO}_{2}$, from gaseous streams generated by industry. Porous carbons supporting $\mathrm{CaO}$ were also reported [18] to be effective for this purpose. However, these composite sorbents were prepared by means of the conventional impregnation of commercial activated carbons with suitable calcium compounds.

$\mathrm{MgO}$ itself and some other magnesium compounds are known to be agents capable to create pores in carbon materials [19]. Therefore, pyrolysis of various carbon precursors with numerous magnesium compounds is considered as a suitable method for preparation of porous carbon materials. Depending on magnesium compound used, obtained nanocarbons can be rich in mesopores or/ and in micropores. As reported in our previous work [20], gases being freed from some $\mathrm{MgO}$ precursors may react with a char formed from carbon precursor and thus play a role as pore creating agents. Recently we reported on the preparation and properties of porous carbons supporting $\mathrm{MgO}$ [13]. These sorbents could be successfully prepared by the heating of a synthetic carbon material mixed with natural magnesite. According to our preliminary results, these hybrid materials reveal a potential to capture $\mathrm{SO}_{2}$ traces from air at room temperature.

Dolomite is a natural carbonate material undergoing thermal decomposition with evolution of $\mathrm{CO}_{2}$. The gas can react with carbon materials like char at ca. $800-850{ }^{\circ} \mathrm{C}$ and thus microporosity can be created [21]. Hence, heating of both the dolomite and suitable carbon precursor was thought to be a suitable route to prepare porous carbon material supporting both $\mathrm{MgO}$ and $\mathrm{CaO}$. Obtained composite materials were examined as regenerable sorbents for $\mathrm{CO}_{2}$. As we noticed, regeneration of the $\mathrm{CO}_{2}$-saturated sorbent materials was accompanied by certain changes in a mass of samples, even the process was carried out in an inert medium. For that reason, despite reporting preparation procedure and properties of obtained hybrid materials, in this work we try to explain mechanism of the $\mathrm{CO}_{2}$ capture and reasons of the mass loss, accompanying the regeneration process.

\section{Experimental}

\section{Materials}

The raw dolomite used in this research was mined from deposits located near Zabkowice (Poland), and its basic chemical composition is given in Table 1. This material served as a source of $\mathrm{MgO}$ and $\mathrm{CaO}$. Before use, the raw dolomite was pulverized and dried for $24 \mathrm{~h}$ in air atmosphere at $140{ }^{\circ} \mathrm{C}$. The commercial grade PET purchased from Boryszew Ltd., (Poland) was chosen to be a carbon precursor. Before use, the material was ground to a form of a fine powder.

\section{Preparations}

At first, the powdered PET was mechanically mixed with the dolomite powder (DOL) in three weight proportions (83:17, 50:50, and 30:70). In order to obtain a homogeneous mixes of these raw materials, each PET/DOL mixture was heated $\left(10{ }^{\circ} \mathrm{C} \mathrm{min}^{-1}\right)$ to $265^{\circ} \mathrm{C}$ under argon gas flow $\left(100 \mathrm{~cm}^{3} \mathrm{~min}^{-1}\right)$ and kept at the final temperature for $1 \mathrm{~h}$. The temperature was high enough to melt PET contained in the mixtures. After cooling down, the obtained solid products were ground and once more subjected to the described fusing/grinding procedure. Subsequently, ca. $15 \mathrm{~g}$ of the pulverized PET/DOL mixtures were placed in a tubular furnace and pyrolysed in an argon atmosphere $\left(100 \mathrm{~cm}^{3} \mathrm{~min}^{-1}\right)$ at temperatures up to either 850 , or 900 , or $1000{ }^{\circ} \mathrm{C}$. In each case, the temperature ramp rate was $10{ }^{\circ} \mathrm{C} \mathrm{min}{ }^{-1}$ and the final temperature was maintained for $1 \mathrm{~h}$. After the thermal treatment, whole system was allowed to cool down to room temperature, and obtained hybrid products were finally ground to a form of a fine powder.

\section{Methods}

The X-ray diffraction (XRD) patterns for the prepared materials were recorded using a Philips X'Pert PRO diffractometer operating with the $\mathrm{Cu} \mathrm{K}_{\alpha}$ radiation $(\lambda=$ $1.54056 \AA$ ). The mean sizes of $\mathrm{MgO}$ and $\mathrm{CaO}$ crystallites were calculated according to Scherrer's formula:

$D=\frac{\lambda}{\beta \cos \theta}$

where $D$ is the mean crystallite size $(\mathrm{nm}), \lambda$ is the wavelength of $\mathrm{Cu}-\mathrm{K}_{\alpha}$ radiation $(\mathrm{nm}), \theta$ is the Bragg's angle $\left(^{\circ}\right)$, 
Table 1 Basic chemical composition of the raw dolomite, with reference to oxides (according to manufacturer's data)

\begin{tabular}{lc}
\hline Compound & Content/wt\% \\
\hline $\mathrm{CaO}$ & 29.44 \\
$\mathrm{MgO}$ & 19.75 \\
$\mathrm{SiO}_{2}$ & 1.43 \\
$\mathrm{Fe}_{2} \mathrm{O}_{3}$ & 0.14 \\
$\mathrm{Al}_{2} \mathrm{O}_{3}$ & 0.11 \\
\hline
\end{tabular}

and $\beta$ is the calibrated width of a diffraction peak at halfmaximum intensity (rad).

All thermogravimetric (TG) analyses were carried out using Netzsch STA 449 C precise thermobalance. In order to examine mass changes accompanying the preparation process, measurements were carried out in argon flow $\left(30 \mathrm{~cm}^{3} \mathrm{~min}^{-1}\right)$. For the evaluation of $\mathrm{CO}_{2}$ uptake by the prepared sorbent materials, $10 \mathrm{mg}$ samples were first preheated under nitrogen flow $\left(99.999 \%, 30 \mathrm{~cm}^{3} \mathrm{~min}^{-1}\right)$ to $110{ }^{\circ} \mathrm{C}$. The temperature was maintained until mass indication became stable. After cooling to $30{ }^{\circ} \mathrm{C}$, the inert gas was replaced with $\mathrm{CO}_{2}\left(99.995 \%, \quad 30 \mathrm{~cm}^{3} \mathrm{~min}^{-1}\right)$. Exposing to this gas at the temperature was continued until constant weight was achieved. Subsequently, the regeneration step was carried out in situ according to two different temperature regimes. For that purpose, $\mathrm{CO}_{2}$ flow was stopped and nitrogen gas was introduced to the system $\left(30 \mathrm{~cm}^{3} \mathrm{~min}^{-1}\right)$. Simultaneously, the temperature was raised $\left(10^{\circ} \mathrm{C} \min ^{-1}\right)$ either to $200{ }^{\circ} \mathrm{C}$ or to $850{ }^{\circ} \mathrm{C}$. The final temperature was maintained until mass indication became stable. After that, the measurements were stopped.

The nitrogen adsorption/desorption isotherms at $77 \mathrm{~K}$ were measured with use of Quadrasorb SI (Quantachrome Instruments, USA) analyzer. Prior to the measurements, samples were degassed by the means of heating at $290{ }^{\circ} \mathrm{C}$ under a high vacuum for $12 \mathrm{~h}$. The specific surface areas ( $S_{\mathrm{BET}}$ ) were determined on the basis of $\mathrm{N}_{2}$ adsorption data by Brunauer-Emmett-Teller (BET) model. In addition, micropore surface areas $\left(S_{\text {micro }}\right)$, external surface areas $\left(S_{\text {ext }}\right)$, and total surface areas $\left(S_{\text {total }}\right)$ were calculated by the $\alpha_{\mathrm{s}}$ method.

\section{Results and discussion}

Thermogravimetric (TG) studies

In order to examine mass changes resulting from heating of used materials, appropriate TG measurements were carried out in argon atmosphere. Changes in mass of the PET, the dolomite, as well as of equivalent mixture of them, are illustrated by TG curves drawn in Fig. 1 .

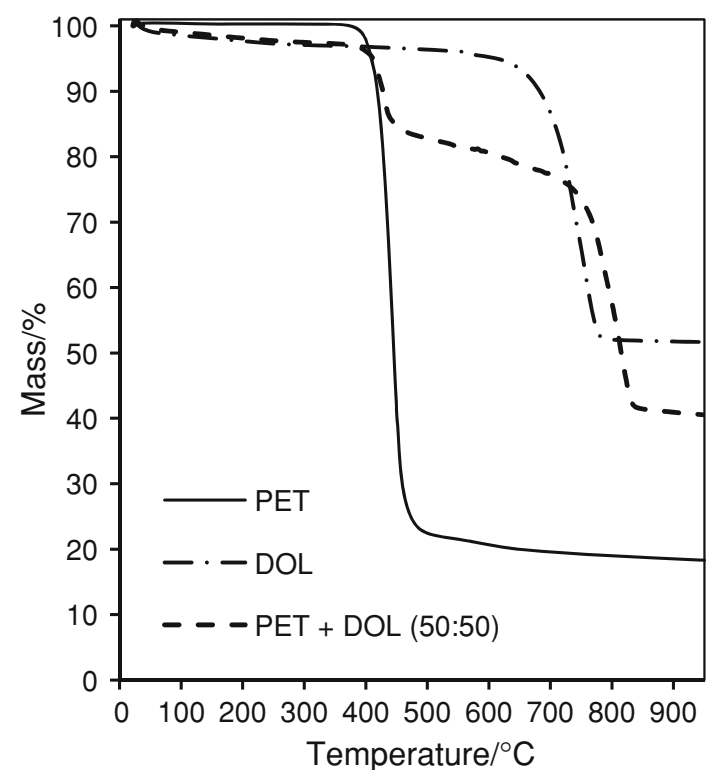

Fig. 1 TG curves for raw PET, raw dolomite (DOL), and raw PET/ DOL (50:50) mixture

The raw PET material reveals a rapid one-step decomposition that could be observed in a temperature range from ca. $380{ }^{\circ} \mathrm{C}$ to ca. $470{ }^{\circ} \mathrm{C}$, with the maximum rate at ca. $420{ }^{\circ} \mathrm{C}$. Similar to PET, the natural dolomite also undergoes one-step decomposition, however, at higher temperatures, i.e., from ca. $610^{\circ} \mathrm{C}$ to ca. $780^{\circ} \mathrm{C}$. The thermogram measured for the PET/DOL mixture confirms two distinct mass drops accompanying the heating. The first decrease in the mass, observed at temperature ca. $420{ }^{\circ} \mathrm{C}$ must be resulting from the thermal decomposition of PET contained in the mixture. The other distinct drop in the mass occurs at temperatures $740-830^{\circ} \mathrm{C}$. Compared to TG results collected for the pure dolomite, this range is slightly shifted to higher temperatures region. Moreover, the residual mass registered after this measurement (41\%) is by $6 \%$ higher than calculated, taking into account residual masses found after heating of PET and DOL alone. Both, the higher than expected residual mass and the shift in temperature of the second drop in the mass, seem to be effects analogous to those observed for systems consisting of PET and thermally decomposable magnesium compounds, described in detail elsewhere [22]. For that reason we did not perform additional research aiming at explanation of these results.

$\mathrm{X}$-ray diffraction $(\mathrm{XRD})$ results

Representative XRD pattern measured for the material obtained through heating of the raw PET/DOL mixture, is shown in Fig. 2. As expected, presence of both $\mathrm{CaO}$ and $\mathrm{MgO}$ as dominating inorganic phases in the sorbent, could be certainly confirmed. Taking into account XRD patterns 


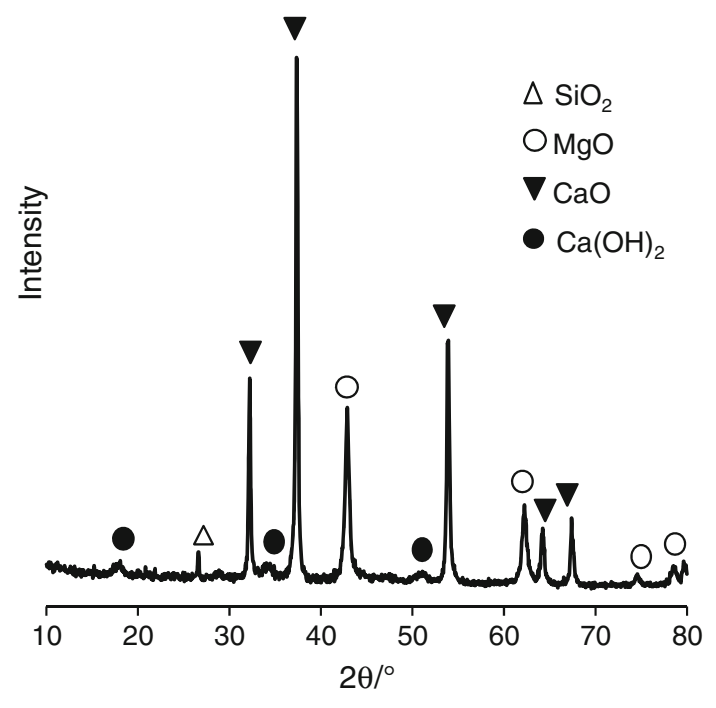

Fig. 2 XRD pattern of the hybrid material obtained through heating of raw PET/DOL (50:50) mixture at $850{ }^{\circ} \mathrm{C}$

measured for the raw dolomite (not shown) and for PET/ DOL mixture subjected to heating (Fig. 2), liberation of $\mathrm{CO}_{2}$ during the preparation process could be easily deduced. Such behavior is a known general feature of many carbonates including dolomite. Hence, $\mathrm{CaO}$ and $\mathrm{MgO}$ are obvious products of the thermal decomposition of the dolomite. Despite the oxides, the XRD pattern measured reveals peaks approving certain content of $\mathrm{SiO}_{2}$ and $\mathrm{Ca}(\mathrm{OH})_{2}$ in the material. The silica is an impurity naturally present in the mineral (Table 1) and certain amounts of calcium hydroxide must be formed through hydration of the hygroscopic $\mathrm{CaO}$ by humidity included in the atmosphere. This apparently takes place during handling of a sample as well as during measurements. All the mentioned phases could be detected also in samples prepared from the other PET/DOL mixtures.

For comparison, sorbent materials were also prepared from the PET/DOL (50:50) mixture at 900 and $1,000{ }^{\circ} \mathrm{C}$. Application of the higher temperatures for preparations did not affect the phase composition of the products. Despite that, the increase in preparation temperature did not cause a significant alteration in the mean size of $\mathrm{CaO}$ and $\mathrm{MgO}$ crystallites (Table 2).

In contrast, mean crystallite sizes determined for these phases, but formed from the sole dolomite, are considerably larger. Formation of the large agglomerates in the solid remained after heating of the dolomite, must be due to easy sintering of neighboring smaller $\mathrm{CaO}$ and $\mathrm{MgO}$ species, remaining in a direct contact during thermal treatment. Analogous observations were reported by others [23] studying reaction of $\mathrm{CO}_{2}$ with lime. On the other hand, the relatively small crystallites found in the hybrid materials must be resulting from an effective separation of fine
Table $2 \mathrm{CaO}$ and $\mathrm{MgO}$ mean crystallite sizes in sorbents prepared from PET/DOL 50:50 at different temperatures and from dolomite heated at $850{ }^{\circ} \mathrm{C}$

\begin{tabular}{lcc}
\hline Preparation temperature $/{ }^{\circ} \mathrm{C}$ & \multicolumn{2}{c}{ Mean crystallite size $/ \mathrm{nm}$} \\
\cline { 2 - 3 } & $\mathrm{CaO}$ & $\mathrm{MgO}$ \\
\hline PET/DOL 50:50 850 & 71.3 & 23.1 \\
PET/DOL 50:50 900 & 56.5 & 22.1 \\
PET/DOL 50:50 1000 & 64.3 & 29.8 \\
DOL 850 & 195.8 & 49.8 \\
\hline
\end{tabular}

dolomite particles by PET material. This reduces possibility of the sintering effect. Thus, formation of the larger species must be diminished. Comparable effects were also observed for other systems, for example composed of carbon and titania [24].

Specific surface areas of the composite materials: an influence of PET/DOL weight ratio and temperature of the preparation process

As displayed on Fig. 3a, relative amounts of PET and dolomite taken for preparations are crucial for nitrogen adsorption at $77 \mathrm{~K}$ on obtained products. Nitrogen uptake at relative pressures below 0.5 , increases markedly along with PET loading in a raw mixture. The shapes of the presented isotherms at the low relative pressure region, like in type I according to IUPAC recommendation [25], indicate the presence of micropores. Despite that, all the isotherms reveal hysteresis loop between adsorption and desorption branches, like in type IV isotherms. This must be due to a capillary condensation characteristic for mesoporous materials. Hence, the shapes of the measured isotherms can be considered as resultant from overlapping of type I and IV isotherms. In contrast, thermal treatment of the raw PET and dolomite at the same temperature, $850{ }^{\circ} \mathrm{C}$, results in obtaining materials revealing very low $\mathrm{N}_{2}$ uptake, Fig. 3b. The char obtained from PET shows negligible $\mathrm{N}_{2}$ adsorption in micropores and adsorption of nitrogen on the solid produced from the sole dolomite proceeds in both micropores and mesopores. For comparison, PET/DOL (50:50)- based sorbent materials were also prepared at higher temperatures, i.e., at 900 and $1,000{ }^{\circ} \mathrm{C}$. Relative position of the measured isotherms (not shown) indicated noticeable decrease in $\mathrm{N}_{2}$ adsorption along with temperature applied for the preparation process. The observations regarding porous structure of all the materials are well reflected by the calculated BET, total, external, and micropore surface areas (Table 3).

Both BET and total specific surface areas determined for all the hybrid materials range from over $100 \mathrm{~m}^{2} \mathrm{~g}^{-1}$ to ca. $350 \mathrm{~m}^{2} \mathrm{~g}^{-1}$, and tend to decrease along with dolomite 
Fig. 3 Nitrogen adsorption/ desorption isotherms (measured at $77 \mathrm{~K}$ ) for a the composite materials prepared at $850{ }^{\circ} \mathrm{C}$ and $\mathbf{b}$ PET and dolomite, both heated at $850{ }^{\circ} \mathrm{C}$ (a)

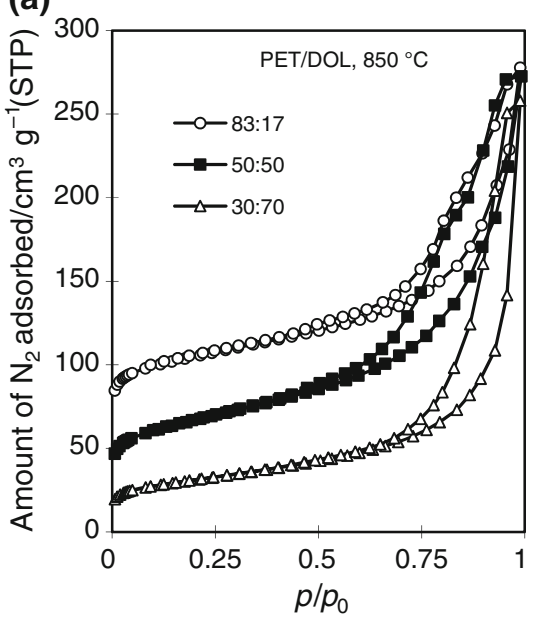

(b)

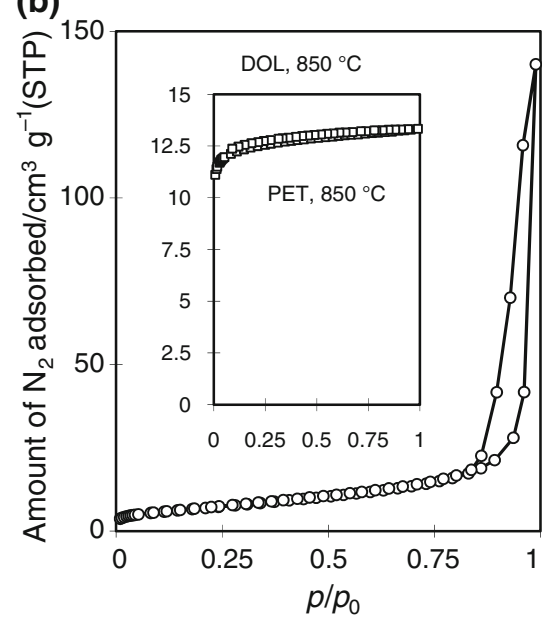

Table 3 Textural parameters calculated from $\mathrm{N}_{2}$ adsorption data, for PET, dolomite, and PET/MAG materials, all heated at $850{ }^{\circ} \mathrm{C}$

\begin{tabular}{|c|c|c|c|c|}
\hline \multirow[t]{2}{*}{ Material $/{ }^{\circ} \mathrm{C}$} & \multirow[t]{2}{*}{$S_{\mathrm{BET}} / \mathrm{m}^{2} \mathrm{~g}^{-1}$} & \multicolumn{3}{|l|}{$\alpha_{\mathrm{s}}$} \\
\hline & & $\overline{S_{\text {total }} / \mathrm{m}^{2} \mathrm{~g}^{-1}}$ & $S_{\mathrm{ext}} / \mathrm{m}^{2} \mathrm{~g}^{-1}$ & $S_{\text {micro }} / \mathrm{m}^{2} \mathrm{~g}^{-1}$ \\
\hline PET/DOL 83:17 850 & 331 & 347 & 111 & 236 \\
\hline PET/DOL 50:50 850 & 221 & 256 & 134 & 123 \\
\hline PET/DOL 30:70 850 & 106 & 114 & 90 & 24 \\
\hline DOL 850 & 25 & 27 & 26 & 1 \\
\hline PET 850 & 34 & 37 & 3 & 34 \\
\hline PET/DOL 50:50 900 & 184 & 203 & 112 & 91 \\
\hline PET/DOL 50:50 1000 & 171 & 188 & 110 & 78 \\
\hline
\end{tabular}

loading in the raw mixtures. Such a trend is known to be resultant from a pore-blocking effect, frequently observed in chemically modified activated carbons or impregnated ones [26]. In the case of PET/DOL-based samples, the regular lowering in pore structure parameters must be caused by increasing contents of $\mathrm{CaO}$ and $\mathrm{MgO}$ crystallites incorporated into the carbon matrix. Considering the values of the external surface areas and micropore areas presented in Table 3, it may be stated that lowering of micropore area is a key reason why the total area decreases along with loadings of the oxides. The mesopore areas of the resultant materials are not much affected by the PET/DOL ratios. An impact of the preparation temperature on the porosity of the sorbent materials is comparable, however, less obvious. Hence, the decrease in micropore area escalating along with preparation temperature is a cause of specific surface area decrease. This is a known trend reported by others [27]. In contrast to the carbon materials loaded with $\mathrm{MgO}$ and $\mathrm{CaO}$, heating of dolomite and PET alone, produces materials revealing very low adsorption of nitrogen and consequently low pore parameters. In view of above observations, an essential role of the dolomite in creation of porosity in the char formed from PET can be evidently concluded. Taking into account the fact that PET/DOL mixtures consist of decomposable carbonate material and both $\mathrm{MgO}$ and $\mathrm{CO}_{2}$ are generated in the mixture during heating, porosity may be developed in processes analogous to those reported in details in our previous work [20]. Hence, mesopores may be due to $\mathrm{MgO}$ and/or $\mathrm{CaO}$ presence while $\mathrm{CO}_{2}$ released from the dolomite may react with the char produced from PET and thus create micropores.

Performance of the composite materials during carbon dioxide capturing and effects accompanying regeneration process

In order to examine capability of the sorbent materials to capture $\mathrm{CO}_{2}$ gas, appropriate tests were carried out using suitable for this purpose [28, 29] precise thermobalance. Results attained for the sorbents prepared from PET/DOL mixtures are presented in Fig. 4. For reference, results of analogous tests carried out for the pyrolysed PET and dolomite are also shown. Materials prepared at $850{ }^{\circ} \mathrm{C}$ were chosen for testing because higher preparation temperatures adversely influenced pore structure parameters of the products. 
Two series of measurements were conducted, both beginning with $\mathrm{CO}_{2}$ adsorption step carried out at $30{ }^{\circ} \mathrm{C}$. However, while desorption of $\mathrm{CO}_{2}$ in nitrogen atmosphere for the first series was conducted at temperatures up to $200{ }^{\circ} \mathrm{C}$ (Fig. 4a), samples subjected to the second series were heated to $850{ }^{\circ} \mathrm{C}$ (Fig. 4b).

In both series of measurements, comparable increases in a mass of the tested samples can be observed during their exposition to $\mathrm{CO}_{2}$. Uptake of the gas markedly increases along with the PET/DOL ratio used for preparations, to achieve ca. $9 \mathrm{wt} \%$ for material holding the lowest amounts of $\mathrm{MgO}$ and $\mathrm{CaO}$ and, at the same time being the richest in carbon material. It should be noticed that at the beginning of $\mathrm{CO}_{2}$ sorption branches, TG curves registered for materials poorer in the oxides are steeper compared to those holding more oxides. This directly confirms an increase in the rate of $\mathrm{CO}_{2}$ sorption by the hybrid sorbents along with the PET/DOL ratio. Taking into account textural parameters (Table 3 ) of the studied composite materials, one may notice a known tendency [30], i.e., an increase in amount and rate of $\mathrm{CO}_{2}$ adsorbed along with micropore area.

In each run, exchanging $\mathrm{CO}_{2}$ with $\mathrm{N}_{2}$ results in a rapid mass drop observable already at the beginning of heating to either 200 or $850{ }^{\circ} \mathrm{C}$. This immediate loss confirms that at least some quantities of total $\mathrm{CO}_{2}$ captured were weakly adsorbed on the sorbent materials. Residual masses of the samples registered after heating to 200 and $850{ }^{\circ} \mathrm{C}$ are very different. As a rule, mass drops determined for the materials exposed to $\mathrm{N}_{2}$ at the lower temperature are lesser compared to those measured for samples heated to $850{ }^{\circ} \mathrm{C}$. Moreover, while $\mathrm{CO}_{2}$-saturated PET/DOL 83:17 sample loses upon heating to $200{ }^{\circ} \mathrm{C}$ ca. $5 \%$ of its mass related changes registered for two other hybrid materials are only ca. $3 \mathrm{wt} \%$ and ca. 0.5 wt\% for PET/DOL 50:50 and PET/ DOL 30:70, respectively. So, the residual mass determined after heating to $200{ }^{\circ} \mathrm{C}$ increases along with $\mathrm{MgO}$ and $\mathrm{CaO}$ loading in the tested material. A noteworthy fact is that the residual masses were always above $100 \%$. This confirms that heating to $200{ }^{\circ} \mathrm{C}$ is not enough for complete regeneration of the $\mathrm{CO}_{2}$-saturated PET/DOL-based materials. In view of above discussion, it may be stated that some part of $\mathrm{CO}_{2}$ captured by the sorbents is fixed weakly due to physical adsorption or weakly chemisorbed, and another portion is bound strongly, presumably due to some chemical interaction between $\mathrm{CO}_{2}$ and the oxides included in the sorbent materials.

Confirmation of this statement comes from results gained for DOL and PET-based samples. $\mathrm{CO}_{2}$ uptakes revealed by the materials are quite low, and reach only ca. $2 \mathrm{wt} \%$. However, both of them behave very different during next steps of the TG measurements. Heating of the first material (originally mixture of mainly $\mathrm{MgO}$ and $\mathrm{CaO}$ ) in nitrogen atmosphere to $200{ }^{\circ} \mathrm{C}$ causes almost no change
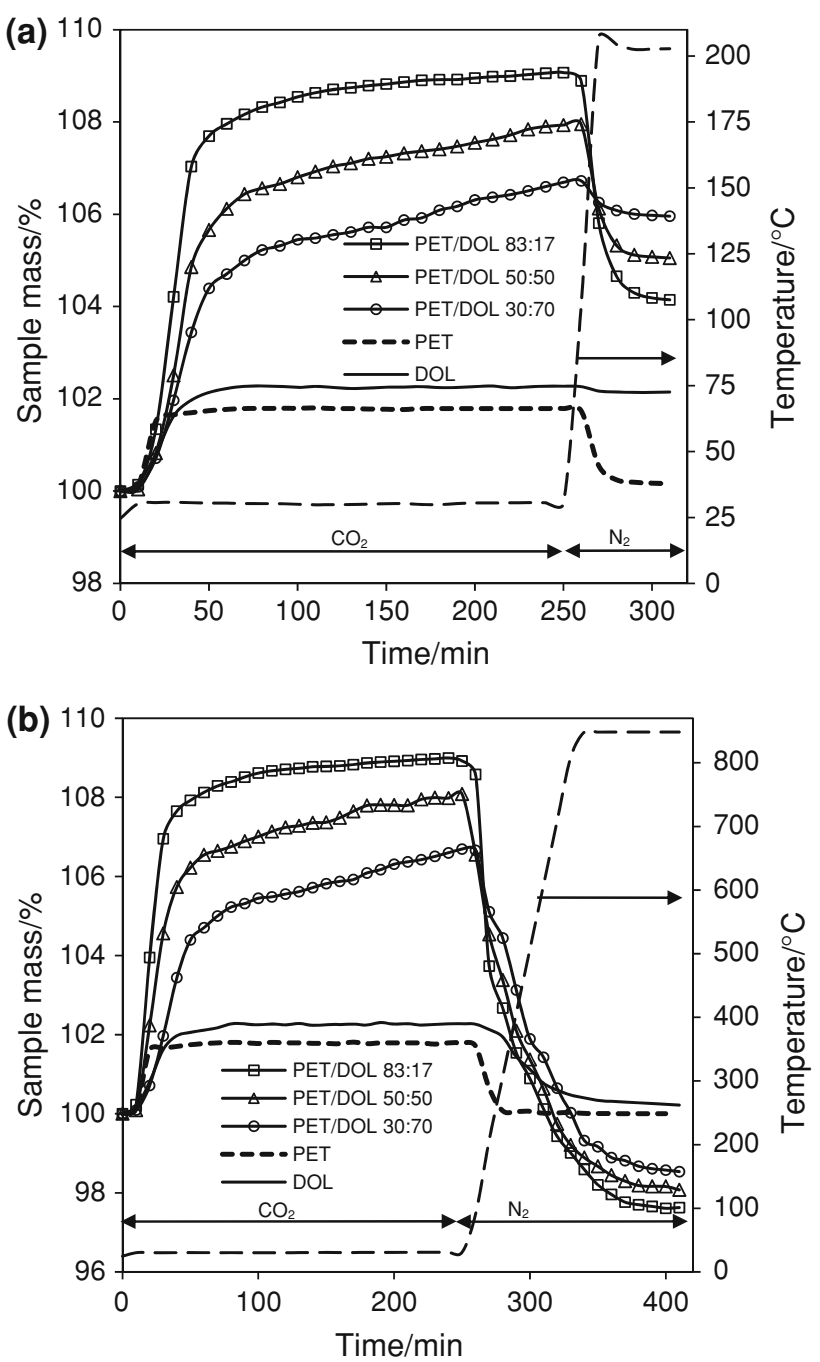

Fig. 4 Results of $\mathrm{CO}_{2}$ sorption (at $30{ }^{\circ} \mathrm{C}$ ) and desorption at a up to $200{ }^{\circ} \mathrm{C}$ and $\mathbf{b}$ up to $850{ }^{\circ} \mathrm{C}$

in the mass. On the other hand, exposing to analogous conditions of the sole char formed from PET results in a complete desorption of the $\mathrm{CO}_{2}$ previously adsorbed. These facts evidently point the oxides as accountable for the strong fixing of the $\mathrm{CO}_{2}$. That is why the hybrid materials richer in $\mathrm{CaO}$ and $\mathrm{MgO}$ fix more $\mathrm{CO}_{2}$ bound strongly. On the other hand, significant amounts of $\mathrm{CO}_{2}$ adsorbed weakly by samples poor in the inorganic additives, must be related to adsorption in micropores. As a consequence, performances of more microporous sorbents, i.e., those containing less $\mathrm{MgO}$ and $\mathrm{CaO}$, are superior in this case.

Following considerations given above, the low $\mathrm{CO}_{2}$ uptake by the mixture of $\mathrm{MgO}$ and $\mathrm{CaO}$ formed from the dolomite seems to be divergent from the trends observed for strong binding of $\mathrm{CO}_{2}$. Because reaction between the solid and the gas is predominantly a surface process, the low performance of the mixture must be resulting from 
comparatively large $\mathrm{CaO}$ and $\mathrm{MgO}$ crystallites, Table 2, [23]. The large species reveal low specific surface area and thus low contact area with an adsorbate. For that reason, amounts of $\mathrm{CO}_{2}$ captured by the sole dolomite-based sorbent is so low. Lack of microporosity in the material must be another reason of the poor performance.

Very interesting and unexpected results were collected for the second series of measurements, Fig. 4b. Heating of the $\mathrm{CO}_{2}$-saturated hybrid materials to $850{ }^{\circ} \mathrm{C}$ is accompanied by an unpredicted reduction of sample mass, to $2-3 \%$ below an original level. On the contrary, heating of the materials obtained from sole PET or sole dolomite, results in expected return of the mass to the initial level, without any additional loss. Hence, desorption of $\mathrm{CO}_{2}$ from the $\mathrm{MgO} / \mathrm{CaO}-$ loaded nanoporous carbons must be accompanied by some processes resulting in the noticeable loss. Considering results of our related studies, the mass decrease observed during heating of the hybrid materials to $850{ }^{\circ} \mathrm{C}$, appears to be due to the gasification of the carbon by the strongly fixed $\mathrm{CO}_{2}$, being freed from the exhausted hybrid materials during regeneration. Proceeding of such reaction was confirmed by temperature programmed desorption studies reported by us in our earlier work [22].

In view of above statements, the hybrid materials supporting more oxides are capable to fix strongly more $\mathrm{CO}_{2}$. As a natural consequence, larger amounts of the gas are released at high temperatures from the sorbents richer in $\mathrm{MgO}$ and $\mathrm{CaO}$. Thus, more $\mathrm{CO}_{2}$ is available for the reaction with the carbonaceous component of the hybrid sorbents while regenerated. In effect, determined mass losses tend to be more apparent for sorbent materials containing more $\mathrm{MgO}$ and $\mathrm{CaO}$. As confirmed by $\mathrm{TG}$ curves in Fig. $4 \mathrm{~b}$, the gasification process considered here can take place only in hybrid sorbents and does not occur when nonhybrid samples, i.e., the char or $\mathrm{MgO} / \mathrm{CaO}$ alone, are examined according to the same manner. Weak adsorption of $\mathrm{CO}_{2}$ and easy desorption of the gas at relatively low temperature must be a reason of why such a loss is not observed for the char alone. On the other hand, the dolomite-based sample consists only of thermally stable oxides and do not contain any carbon material. For that reason, no additional loss due to carbon gasification by the $\mathrm{CO}_{2}$ can take place even the gas is strongly fixed and released at high temperature.

\section{Conclusions}

Results described in this work led us to several important findings and conclusions. The preparation method proposed is simple and readily available raw materials can be used. We confirmed that employing natural dolomite for preparations may result in twofold benefit. During preparations, the mineral undergoes thermal decomposition to $\mathrm{MgO}$ and $\mathrm{CaO}$ and to $\mathrm{CO}_{2}$ gas. These products are capable to create either mesopores or micropores in suitable carbon materials, like the char formed from PET. Hence, dolomite may act as a specific activating agent to produce porous carbons from the synthetic precursor. The second advantage is that the oxides remain in the structure of the product and play a role of a specific agents enhancing sorption of acidic adsorbates like $\mathrm{CO}_{2}$.

Because resultant sorbent materials reveal significant microporosity, a part of the total amount of $\mathrm{CO}_{2}$ captured is weakly fixed. On the other hand, presence of the metal oxides results in proceeding of a chemical interactions resulting in a strong binding of the gas. In both cases, heating of the $\mathrm{CO}_{2}$-saturated hybrid sorbents in an inert atmosphere results in desorption of the gas. However, while physisorbed $\mathrm{CO}_{2}$ can be released easily at relatively low temperature, portions of the gas fixed strongly require much more drastic conditions to be desorbed. Thus, $\mathrm{CO}_{2}$ captured by the sorbents can be released in a controlled way: a part of $\mathrm{CO}_{2}$ can be desorbed at low temperatures, and the other parts, strongly bound, require more rigorous temperature conditions to be desorbed.

The sorbents studied can be regenerated and therefore be used more than one time. However, because a part of carbon material is lost during regeneration process, the contents of $\mathrm{MgO}$ and $\mathrm{CaO}$ contained the in regenerated material must gradually increase. This may entail changes in parameters and in performance of the sorbent.

Acknowledgements This study was supported by the Polish Ministry of Science and Higher Education, Grant No. N R050004 10.

Open Access This article is distributed under the terms of the Creative Commons Attribution License which permits any use, distribution, and reproduction in any medium, provided the original author(s) and the source are credited.

\section{References}

1. Przepiórski J. Activated carbon filters and their industrial applications. In: Bandosz TJ, editor. Activated carbon surfaces in environmental remediation. New York: Academic Press; 2006. p. 421-74.

2. Karatepe N, Orbak I, Yavuz R, Ozyuguran A. Sulfur dioxide adsorption by activated carbons having different textural and chemical properties. Fuel. 2008;87:3207-15.

3. Hsieh CT, Teng H. Influence of mesopore volume and adsorbate size on adsorption capacities of activated carbons in aqueous solutions. Carbon. 2000;38:863-9.

4. Zhao XS, Cai GY, Wang ZZ, Wang QX, Yang YH, Luo JS. Influences of surface functional groups on catalytic activity over activated carbon catalysts for sulfur dioxide removal from flue gases. Appl Catal B. 1994;3:229-38.

5. Shafeeyan MS, Ashri Wan Daud WM, Houshmand A, Shamiri A. A review on surface modification of activated carbon for carbon dioxide adsorption. J Anal Appl Pyrol. 2010;89:143-51. 
6. Mourão PAM, Laginhas C, Custódio F, Nabais JMV, Carrott PJM, Ribeiro Carrott MML. Influence of oxidation process on the adsorption capacity of activated carbons from lignocellulosic precursors. Fuel Process Technol. 2011;92:241-6.

7. Pacewska B, Szychowski D. Mineral-carbon sorbents based on post-decarbonization lime and mixture of hydrocarbons. J Therm Anal Calorim. 2005;80:687-93.

8. Szmigielski R, Zietek S, Swiatkowski A, Palijczuk D, Kielczewski M. Non-carcinogenic carbon sorbents for respiratory protection. J Hazard Mater. 2009;163:471-4.

9. Kang YH, Shiue A, Hu SC, Huang CY, Chen HT. Using phosphoric acid-impregnated activated carbon to improve the efficiency of chemical filters for the removal of airborne molecular contaminants (AMCs) in the make-up air unit (MAU) of a cleanroom. Build Environ. 2010;45:929-35.

10. Choi JS, Kim TH, Choo KY, Sung JS, Saidutta MB, Ryu SO, Song SD, Ramachandra B, Rhee YW. Direct synthesis of phenol from benzene on iron-impregnated activated carbon catalysts. Appl Catal A. 2005;290:1-8.

11. Bylina IV, Tong S, Jia CQ. Thermal analysis of sulphur impregnated activated carbons with mercury adsorbed from the vapour phase. J Therm Anal Calorim. 2009;96:91-8.

12. Przepiórski J, Yoshida S, Oya A. Structure of $\mathrm{K}_{2} \mathrm{CO}_{3}$-loaded activated carbon fiber and its deodorization ability against $\mathrm{H}_{2} \mathrm{~S}$ gas. Carbon. 1999;37:1881-90.

13. Przepiorski J, Czyzewski A, Kapica J, De la Casa-Lillo MA. Preparation and properties of porous carbon material containing magnesium oxide. Pol J Chem Technol. 2011;13:42-6.

14. Qiang T, Zhigang Z, Wenpei Z, Zidong C. $\mathrm{SO}_{2}$ and $\mathrm{NO}$ selective adsorption properties of coal-based activated carbons. Fuel. 2005;84:461-5.

15. Zhao HY, Cao Y, Lineberry Q, Pan WP. Evaluation of $\mathrm{CO}_{2}$ adsorption capacity of solid sorbents. J Therm Anal Calorim. 2011;106:199-205.

16. Bhagiyalakshmi M, Lee JY, Jang HT. Synthesis of mesoporous magnesium oxide: its application to $\mathrm{CO}_{2}$ chemisorption. Int $\mathrm{J}$ Greenh Gas Control. 2010;4:51-6.

17. Stolaroff JK, Lowry GV, Keith DW. Using $\mathrm{CaO}$ - and $\mathrm{MgO}$-rich industrial waste streams for carbon sequestration. Energy Conv Manag. 2005;46:687-99.

18. Macías-Pérez MC, Bueno-López A, Lillo-Ródenas MA, De Salinas-Martínez LC, Linares-Solano A. $\mathrm{SO}_{2}$ retention on $\mathrm{CaO} /$ activated carbon sorbents. Part III. Study of the retention and regeneration conditions. Fuel. 2008;87:3170-5.

19. Morishita T, Tsumura T, Toyoda M, Przepiórski J, Morawski AW, Konno H, Inagaki M. A review of the control of pore structure in MgO-templated nanoporous carbons. Carbon. 2010;48:2690-707.

20. Przepiorski J, Karolczyk J, Takeda K, Tsumura T, Toyoda M, Morawski AW. Porous carbon obtained by carbonization of PET mixed with basic magnesium carbonate: pore structure and pore creation mechanism. Ind Eng Chem Res. 2009;48:7110-6.

21. Guo S, Peng J, Li W, Yang K, Zhang L, Zhang S, Xia H. Effects of $\mathrm{CO}_{2}$ activation on porous structures of coconut shell-based activated carbons. Appl Surf Sci. 2009;255:8443-9.

22. Przepiorski J, Karolczyk J, Tsumura T, Toyoda M, Inagaki M, Morawski AW. Effect of some thermally unstable magnesium compounds on the yield of char formed from poly(ethylene terephthalate). J Therm Anal Calorim. 2012;107:1147-54.

23. Abanades JC, Alvarez D. Conversion limits in the reaction of $\mathrm{CO}_{2}$ with lime. Energy Fuels. 2003;17:308-15.

24. Tsumura T, Kojitani N, Izumi I, Iwashita N, Toyoda M, Inagaki M. Carbon coating of anatase-type $\mathrm{TiO}_{2}$ and photoactivity. J Mater Chem. 2002;12:1391-6.

25. IUPAC. Commission on colloid and surface chemistry including catalysis. Pure Appl Chem. 1985;57:603-19.

26. Sumathi S, Bhatia S, Lee KT, Mohamed AR. Selection of best impregnated palm shell activated carbon (PSAC) for simultaneous removal of $\mathrm{SO}_{2}$ and $\mathrm{NO}_{\mathrm{x}}$. $\mathrm{J}$ Hazard Mater. 2010;176: 1093-6.

27. Blazewicz S, Swiatkowski A, Trznadel BJ. The influence of heat treatment on activated carbon structure and porosity. Carbon. 1999;37:693-700

28. Barbosa MN, Araujo AS, Galvão LPFC, Silva EFB, Santos AGD, Luz GE Jr, Fernandes VJ Jr. Carbon dioxide adsorption over DIPA functionalized MCM-41 and SBA-15 molecular sieves. J Therm Anal Calorim. 2011;106:779-82.

29. Lwin Y, Abdullah F. High temperature adsorption of carbon dioxide on $\mathrm{Cu}-\mathrm{Al}$ hydrotalcite-derived mixed oxides: kinetics and equilibria by thermogravimetry. J Therm Anal Calorim. 2009;97: 885-9.

30. Plaza MG, Pevida C, Martín CF, Fermoso J, Pis JJ, Rubiera F. Developing almond shell-derived activated carbons as $\mathrm{CO}_{2}$ adsorbents. Sep Purif Technol. 2010;71:102-6. 